Анна Кулькова

\title{
РЕЛИГИЯ И СОЦИАЛЬНАЯ СПРАВЕДЛИВОСТЬ: ОБЗОР ИССЛЕДОВАНИЙ ВЛИЯНИЯ РЕЛИГИОЗНОСТИ НА ПРЕДПОЧТЕНИЯ ОТНОСИТЕЛЬНО СОЦИАЛЬНОЙ ПОЛИТИКИ
}

Масштабы социальной политики зависят от уровня развития государства, которым определяется, какое количество ресурсов государство может перераспределять и направлять на помощь нуждающимся. Однако проводимая социальная политика также зависит и от предпочтений граждан, их представлений о необходимости помощи определенным социальным группам, о степени допустимого вмешательства государства в экономику. В отличие от исследований, которые объясняют различия в предпочтениях относительно социальной политики через социально-экономические факторы, в фокусе этого обзора исследований находится религия как культурный предиктор восприятия государства благосостояния. Религия может оказывать воздействие на индивидуальные предпочтения относительно перераспределения благ, как создавая общий культурный контекст и задавая некий стандарт помощи нуждающимся, так и определяя индивидуальные установки верующих относительно того, кто заслуживает помощи и как она должна осуществляться. Статья представляет собой обзор механизмов влияния религии на формирование индивидуальных предпочтений относительно социальной политики, в котором на основании существующих исследований анализируется, существуют ли различия в отношении к социальной политике между последователями разных религиозных традиций, а также между религиозными и нерелигиозными людьми в современной Европе. Сначала религия рассматривается как фактор контекстуального уровня, и в фокусе оказывается влияние церковно-государственных отношений и содержательной стороны доминирующей религиозной традиции на формирование принципиально разного отношения к бедности и, как следствие,

Анна Кулькова - младший научный сотрудник, Научно-учебная лаборатория политических исследований, НИУ ВШЭ, Москва, Россия. Электронная почта: akulkova@hse.ru 
разных режимов благосостояния в странах Европы. Затем религия рассматривается как предиктор индивидуального уровня, и анализируется, как на предпочтения относительно перераспределения благ влияет степень индивидуальной религиозности.

Ключевые слова: религия, социальная политика, предпочтения относительно перераспределения, восприятие государства благосостояния

DOI: 10.17323/727-0634-2018-16-2-251-264

Государство благосостояния находится в фокусе политической науки уже не одно десятилетие: этой концепции неоднократно диагностировали критическое состояние, предрекая скорую смерть (Esping-Andersen et al. 2002). Однако и в XXI в. споры вокруг государственной политики перераспределения благ не утихают, особенно обостряясь в периоды кризисов и реформ. Очевидные проблемы в реализации мер социальной политики рождают дискуссии о том, кому и как государство должно помогать, перераспределяя деньги налогоплательщиков (Van Oorschot 2000, 2006). Ключевым для данной статьи термином являются предпочтения относительно государственного перераспределения ресурсов, а в качестве синонимов используются такие понятия как отношение к политике благосостояния (welfare attitudes), объем социальных благ и восприятие социальной роли государства. Все эти термины активно используются в современной литературе и в целом подразумевают под собой предпочитаемое индивидами соотношение между размером налогов, которые они платят в бюджет, и объемом социальных благ, которые государство предоставляет гражданам взамен (Kumlin 2007).

Современное государство благосостояния обычно преследует две цели: перераспределение ресурсов и обеспечение социальных гарантий (Alesina, Giuliano 2011). Масштабы социальной политики, безусловно, зависят от уровня развития государства, которым определяется, какое количество ресурсов государство может перераспределять и направлять на помощь нуждающимся. Сложившиеся институты благосостояния формируют и поддерживают представления индивидов о том, как эти институты должны функционировать, однако, с другой стороны, проводимая социальная политика зависит и от предпочтений граждан, их представлений о необходимости помощи определенным социальным группам, о степени допустимого вмешательства государства в экономику (Pfau-Effinger 2005). В литературе доминируют работы, которые объясняют различия в отношении к социальной политике через социально-экономическое положение индивида. Так, на формирование предпочтений относительно перераспределения могут влиять индивидуальные (Cook, Barrett 1992; Mau 2004; Sanders 1988) и классовые (Iversen, Soskice 2001; Svallfors 2006) экономические интересы; опыт безработицы, взаимодействия с государством 
и получения помощи (Alesina, Giuliano 2011; Giuliano, Spilimbergo 2014; Lipsmeyer, Nordstrom 2003); или идеология (Alesina, Fuchs-Schundeln 2006).

В логике перечисленных теорий более уязвимые слои населения должны поддерживать политику перераспределения и голосовать за левые партии (тем самым обеспечивая себе социальные гарантии), однако в реальности бедные часто голосуют «неестественно» - за консервативные партии, продвигающие снижение налогового бремени и, соответственно, уменьшение финансирования социальных программ. Подобное «неестественное» электоральное поведение объясняется тем, что индивидуальные предпочтения зависят не только от экономических реалий или принадлежности к определенному классу, но также могут быть следствием сложившейся в стране культуры и массовых представлений о том, какой должна быть социальная политика (Achterberg, Houtman 2006). Так, например, в сравнительных страновых исследованиях государства благосостояния одной из самых популярных тем являются причины различий в объемах социальной помощи между США и странами Европы. В США государственные программы по предоставлению социальной помощи нацелены на самые бедные слои населения, так как после достижения индивидом определенного уровня дохода он более не имеет права на доступ к социальным сервисам, в то время как в Европе, особенно в Скандинавии, доступ к социальным сервисам имеют все граждане. Альберто Алесина и Эдвард Глейзер связывают различия в моделях государства благосостояния с культурой и разным отношением к бедности в этих странах (Alesina, Glaeser 2004). В США больше распространена индивидуалистическая модель, подразумевающая, что жизненный успех определяется персональными усилиями, а бедные сами ответственны за свое положение. С другой стороны, европейцы, даже при учете страновых различий в восприятии бедности, в среднем склонны связывать бедность с неэффективностью институтов и/или социальными условиями. Культурный контекст может влиять на индивидуальные предпочтения относительно перераспределения благ не только через формирование восприятия причин бедности, но и через разграничение «своих» и «чужих». Работы, изучающие последствия гетерогенности в обществе, показывают, что альтруизм не выходит за границы культурных групп: люди готовы финансово поддерживать «своих», но использование налогов для финансовой помощи «чужим» вызывает негативную реакцию (Alesina et al. 2003; Stegmueller 2013). В культурно гомогенных странах Скандинавии расширение социальной политики встретило гораздо меньше сопротивления, чем в США, где сосуществовать приходится разным культурным группам.

В отличие от большинства исследований, которые объясняют различия в предпочтениях относительно социальной политики через социально-экономические факторы, в фокусе этого обзора находится религия как культурный предиктор восприятия государства благосостояния. Религия может оказывать воздействие на индивидуальные предпочтения 
относительно перераспределения, как создавая общий культурный контекст и задавая некий стандарт помощи нуждающимся, так и определяя индивидуальные установки верующих относительно того, кто заслуживает помощи и как она должна осуществляться. Чтобы политические последствия религий для предпочтений индивидов относительно перераспределения можно было сравнивать, в фокус статьи попадают исключительно страны Европы с доминированием христианства.

Статья представляет собой обзор механизмов влияния религии на формирование индивидуальных предпочтений относительно социальной политики. Сначала религия рассматривается как фактор контекстуального уровня, и в фокусе оказывается влияние церковно-государственных отношений и содержательной стороны доминирующей религиозной традиции на формирование разного отношения к бедности и, как следствие, разных режимов благосостояния в странах Европы. Затем мы перейдем к религии как предиктору индивидуального уровня и рассмотрим, как на предпочтения относительно перераспределения благ влияет степень индивидуальной религиозности. Иными словами, на основании исследований по теме осуществляется поиск ответа на вопрос о различиях в отношении к социальной политике между последователями разных религиозных традиций, а также между религиозными и нерелигиозными людьми в современной Европе.

\section{Влияние религиозных традиций: исторический экскурс в отношения церкви и государства и развитие государства благосостояния}

Различия в нормах и ценностях, определяющие отношение к бедности и политике перераспределения, могут быть вызваны как культурными традициями и личным опытом, так и влиянием религиозных доктрин не только на индивидуальные предпочтения, но и на эволюцию государственных институтов. В своей типологии Госта Эспинг-Андерсен на основании степени вмешательства государства в экономику и масштабов политики перераспределения выделил три идеальных типа государств благосостояния: либеральный, консервативный и социально-демократический (Esping-Andersen 2013). Автор связывает различия между выделенными моделями с классовыми конфликтами и историческими особенностями становления политических режимов, то есть преимущественно с социально-политическими факторами. Однако эти модели государств благосостояния накладываются и на границы религиозных деноминаций в Европе. Так, либеральный режим характерен для государств, формировавшихся под влиянием кальвинизма (крайне ограниченное вмешательство государства, помощь только самым бедным), например, для Швейцарии, которая после 1970-х гг. постепенно перешла к консервативной модели (Obinger et al. 2010). Последняя наблюдается в преимущественно католических странах (доминирование схем социального 
страхования, опора на семью) например, во Франции, а социально-демократический тип социального государства (сильное вмешательство, широкая социальная политика) соответствует северным лютеранским странам (Gorski 2003; Kahl 2005, 2009; Van Kersbergen 2003; Van Kersbergen, Manow 2009). Для этой статьи выделенные модели капитализма представляют интерес, поскольку иллюстрируют, как различия в доминирующих религиозных традициях и отношениях между церковью и государством могут привести к формированию абсолютно разных режимов обеспечения благосостояния и заложить разграничение обязанностей политических акторов в вопросах реализации социальной политики. Далее мы рассмотрим, почему именно такие режимы благосостояния сформировались в этих странах, проанализировав литературу об отношении доминирующих в странах религиозных традиций к бедности, а также о сложившихся отношениях между церковью и государством по вопросам помощи нуждающимся. Особое внимание уделяется тому, какой актор (государство или церковь) преимущественно реализовывал социальную политику на ранних этапах формирования систем помощи нуждающимся, а также степень конфликтности церковно-государственных отношений по вопросам перераспределения.

В странах Юго-Западной Европы католическая церковь еще со Средних веков играла ведущую роль в обеспечении благосостояния, что в те времена выражалось в оказании медицинской и финансовой помощи нуждающимся (Brodman 2009). Для финансирования поддержки бедных церковь активно привлекала богатых, для которых благотворительность позиционировалась как шанс искупить свои грехи. Официальная доктрина церкви закрепила моральные (на самом деле финансовые) обязательства общества и богатых перед бедными (Kahl 2005). Более того, на протяжении веков католическая церковь являлась мощной политической и финансовой структурой, с которой светским руководителям государств приходилось договариваться о разграничении обязанностей, при этом церковь предпочитала самостоятельно контролировать ресурсы благотворительности, не допуская в нее государство.

Если историю отношений католической церкви со светскими правителями можно охарактеризовать как острое соперничество за власть и ресурсы, а также принципиальное доминирование церкви в обеспечении благосостояния, то в преимущественно лютеранских странах Северной Европы отношения между церковью и светскими правителями начиная с Реформации складывались по-другому. В этот период особой критике подвергалась финансовая политика католической церкви: с одной стороны, чрезмерные траты на «образ жизни» и оформление храмов, с другой - продажа индульгенций грешникам как основной способ финансирования деятельности церкви. Католическая политика помощи бедным также попала под огонь критики со стороны протестантов: католикам общественный долг диктовал помогать всем нуждающимся, а протестанты задумались о том, кто же действительно 
заслуживает помощи. Если в католицизме принципиальной была ответственность общества за жизненные неудачи отдельных индивидов, особенно за бедность, то Мартин Лютер обращал внимание на необходимость индивидуальной ответственности, как в земных, так и религиозных вопросах, а также позиционировал личную веру как единственно возможный путь к спасению (Kahl 2005). Лютеранские церкви исторически формировались и развивались в сотрудничестве со светскими властями (Gustafsson 2003; Madeley 2003). Таким образом, долгая традиция сотрудничества между государством и церковью привела к формированию современной системы взаимодействия, когда лютеранская церковь в Скандинавии, по сути, является государственным агентством: получают финансирование из бюджета и предоставляют услуги населению. Так, в Швеции государственная церковь получает бюджетное финансирование на проведение похорон и содержание кладбищ. Отношения между церковью и государством в Северной Европе характеризовались как бесконфликтные даже в начале XX в., когда государство начало забирать себе социальные функции (например, образование), которые раньше реализовывали церкви (Van Kersbergen, Manow 2009).

Специфическое для протестантизма смещение акцента с ответственности общества перед человеком на индивидуальную ответственность нашло отражение в доктринах реформатских церквей (последователи кальвинистской традиции). Исторически реформаты нигде не составляли большинства и подвергались гонениям со стороны государства, в результате чего для них характерно недоверие к светским властям, а также акцент на индивидуализм и самопомощь (Manow 2004). Именно для последователей кальвинизма свойственно восприятие жизненного успеха как признака избранности к спасению, а неудач - как следствия морального разложения. Более того, если больные и старые в этой логике могут рассчитывать на помощь общества, то безработные несут индивидуальную ответственность за свою судьбу, и общество им помогать не обязано (Cohen 2002: 119). Из-за негативного опыта взаимодействия с государством, а также из-за отрицания необходимости помощи бедным развитие социальных государств затруднено не только там, где последователи реформатских церквей преобладали, но и там, где они вынуждены соперничать с другими религиозными традициями. Так, реформаты сдерживали расширение социальной политики в Великобритании, Швейцарии и Нидерландах, через политические партии противодействуя принятию слишком «коллективистских» социальных программ, которые бы чрезмерно расширили полномочия государства (Catterall 1993; Obinger 2009; Van Kersbergen 2009).

В оригинальной классификации государств благосостояния ЭспингАндерсен рассматривал исключительно развитые страны Запада (Европу, США, Канаду, Австралию), а страны Восточной Европы на момент публикации книги в 1990 г. переживали политические и экономические трансформации и в анализ не попали. Именно в Восточной Европе множество 
стран с доминированием православного христианства, которое имеет специфические паттерны взаимоотношений между церковью и государством. Безусловно, на эволюцию социальной политики в православных странах Восточной Европы повлиял коммунистический период, равно как и на положение церкви, однако история развития церковно-государственных отношений имеет много общего для посткоммунистических православных стран и средиземноморских Греции и Кипра, хотя современные модели взаимодействия церкви и государства по социальным вопросам могут различаться. Сложившаяся в православных странах модель разделения полномочий между религиозными и светскими институтами в деле помощи нуждающимся противоположна странам с доминированием католической традиции. В политической теологии православия в явном виде идея отделения церкви от государства отсутствует, зато получила поддержку и многократную реализацию идея совмещения власти духовной и светской в одних руках. Так как у православных церквей де факто нет сильного наднационального руководства, исторически они не смогли противостоять политическому влиянию светских правителей: раздробленные и изолированные автокефальные церкви впали в политическую (например, назначение церковных иерархов) и финансовую зависимость от государства - Российская империя при Петре I и далее, Болгария, Румыния, Греция (MolokotosLiederman, Fokas 2010; Philpott 2007). Хотя, с точки зрения православия, необходимость помощи бедным и не вызывает вопросов, зависимые церкви, особенно ослабевшие в коммунистический период в соответствующих странах, не стали оспаривать право государства на осуществление этой помощи (Alesina, Giuliano 2011). Таким образом, православие повлияло только на индивидуальное восприятие бедности, но не на формирование системы помощи нуждающимся, поскольку церкви принимали доминирующую роль государства в реализации социальной политики.

С точки зрения католицизма, общество несет ответственность за бедных и их неудачи, соответственно, общество (и особенно богатые) должно через церковь помогать нуждающимся. Между государством и католической церковью был политический конфликт не только из-за ресурсов, но и кто из акторов кониролирует бюджет. Лютеране обращают внимание на моральные качества нуждающихся и вводят разделение на достойных и не достойных помощи. Перераспределение ресурсов в этой модели осуществляет государство, а церкви выступают как государственные агентства. Соответственно, конфликт между церковью и государством в культурно гомогенных лютеранских странах отсутствует в принципе. С другой стороны, для реформатов (кальвинистов) характерно суровое отношение к бедности и возложение ответственности за жизненные неудачи на самих индивидов. Возможности государства в этой модели ограничены из-за недоверия реформатов государственным институтам. Наконец, для православных свойственно схожее с католиками отношение к бедности, однако именно 
государству в этой модели отводится доминирующая роль, поскольку слабые церкви не могли конкурировать с государствами.

Режимы благосостояния складывались в периоды, когда религия играла важную роль в жизни европейцев. Однако и сегодня, несмотря на значительное уменьшение количества верующих, доминирующая религиозная традиция по-прежнему может влиять на массовые культурные установки, действуя, например, через СМИ, систему образования или через формирование партийной системы - создание христианских политических партий, вдохновленных католической церковью (Catterall 1993; Hudson, Coukos 2005; Kahl 2009; Kalyvas, Van Kersbergen 2010; Manow 2004). Культурное влияние религии на политические и социальные ценности общества может быть настолько обширным, что будет распространяться даже на нерелигиозных индивидов. Вне зависимости от того, религиозен человек или нет, доминирующая религиозная традиция является очень сильным эмпирическим предиктором того, как он/ она будет интерпретировать причины бедности и насколько позитивно будет относиться к идее перераспределения ресурсов именно государством (Cohen 2002). Так, например, жители преимущественно католических стран с большей вероятностью связывают бедность с несправедливостью в обществе, чем с недостатком индивидуальных усилий (Lepianka et al. 2010).

\section{Влияние индивидуальной религиозности на предпочтения относительно перераспределения}

Рассмотренные в исторической ретроспективе формы взаимодействия церкви и государства повлияли на становление государственных институтов обеспечения благосостояния, однако сохранилось ли влияние религиозных доктрин на предпочтения современных индивидов, особенно в условиях секуляризации? Православные традиции и католические учения оправдывают перераспределение в пользу бедных, а акцент протестантизма на индивидуальной ответственности и самопомощи, напротив, приводит к критике социальной политики перераспределения (McCleary 2007). Можно предположить, что католики и православные более позитивно настроены по отношению к перераспределению благ, чем последователи реформированного протестантизма, однако ряд современных работ показывает, что процессы секуляризации нивелировали политические различия между протестантами и католиками (Stegmueller 2013). Так, например, политические партийные расколы в Европе не основаны на доктринальных различиях разных религиозных традиций, поскольку современные христианско-демократические партии, которые изначально ориентировались на католиков, стремятся привлечь всех консервативных избирателей, для чего апеллируют к общехристианским принципам (Bréchon 2003; Kalyvas, Van Kersbergen 2010; Minkenberg 2010). Религия и религиозные институты играют все меньшую роль в формировании политических предпочтений, особенно в сфере экономики, которая 
сейчас регулируется преимущественно светскими интересами (Bruce 2002). Альберто Алесина и Паола Джулиано находят статистически значимые различия между конфессиями: в их исследовании протестанты, католики и буддисты в среднем менее склонны поддерживать перераспределение благ в сравнении с нерелигиозными людьми, в то время как православные христиане даже более позитивно относятся к перераспределению, чем атеисты (Alesina, Giuliano 2011). Тем не менее эти результаты можно и нужно воспринимать критически, так как авторы не контролировали уровень религиозности последователей разных традиций (насколько регулярно они посещают религиозные службы и насколько для них вообще важна религия), хотя это существенно: большинство православных христиан проживают в посткоммунистических странах с прерванной религиозной традицией, где принадлежность к православию воспринимается скорее как культурная, нежели религиозная, идентичность.

Не найдя различий между конфессиями в современном мире, можно было бы сделать вывод, что религия теперь не важна для формирования предпочтений относительно социальной политики, однако исследования показывают наличие нового, не менее важного раскола - между религиозными и нерелигиозными индивидами (Arikan 2013; Chen, Lind 2005; Pepinsky, Welborne 2011; Scheve, Stasavage 2006; Stegmueller 2013). Религиозность оказывает негативное влияние на отношение к социальной политике: нерелигиозные европейцы статистически более склонны поддерживать политику перераспределения благ, чем религиозные, и разрыв между этими группами растет с увеличением степени религиозности.

Почему же религиозность негативно влияет на поддержку перераспределения благ? Во-первых, это может быть связано с тем, что религиозные люди не нуждаются в сервисах и пособиях, предоставляемых государством. Дэниел Чен и Джо Линд предлагают рассматривать религию как систему социального страхования, альтернативную государственной. С точки зрения этой теории, в случае болезни или потери работы более эффективно поможет религиозная община, а не государство. Таким образом, чем меньше денег отдается государству в форме налогов, тем больше члены общины могут направить на самопомощь (Chen, Lind 2005). Во-вторых, помимо социального страхования и помощи общины, религия может предложить еще и психологический страховой механизм. С такой точки зрения, религия помогает справляться с неожиданными серьезными проблемами, такими как безработица, болезнь или потеря трудоспособности, которые ведут не только к материальным издержкам (падение дохода), но и к издержкам психологическим - влияют на самооценку (Scheve, Stasavage 2006). Так, например, в Европе религиозные люди демонстрируют более высокий уровень удовлетворенности жизнью и меньше страдают от потери работы (Clark, Lelkes 2005). В-третьих, верующие могут не одобрять не саму идею помощи бедным, но идею системы перераспределения, управляемой светским государством. 
Государство перераспределяет ресурсы на основании прав человека, но не его моральных качеств, которые важны для религиозных людей (Stegmueller 2013). Если помощь бедным оказывается через добровольные пожертвования, верующие сами могут решать, кто достоин поддержки. Дэниел Стегмюллер находит, что и католики, и протестанты негативно относятся к государственному перераспределению, а разница между конфессиями гораздо меньше, чем между религиозными и нерелигиозными людьми. Наконец, негативная взаимосвязь между индивидуальной религиозностью и отношением к политике перераспределения может объясняться и недовольством государственными институтами, качеством предоставления социальных услуг в сравнении с религиозными некоммерческими организациями (Pepinsky, Welborne 2011).

Можно было бы сделать вывод, что религиозность всегда влияет на отношение к перераспределению негативно, однако ряд исследований показывает, что это не совсем так. Например, в США религиозность поддерживает две идеи, которые могут иметь разнонаправленные политические последствия: необходимость быть «хорошим консерватором» (т.е. ратовать за «минимальное государство») в противовес необходимости помогать нуждающимся (Malka et al. 2011). С другой стороны, в определенных условиях религия не только посылает своим последователям разнонаправленные импульсы, но даже может улучшить отношение к государственной политике перераспределения среди христиан, принадлежащих к доминирующей в стране религиозной традиции (Chen, Lind 2005). Так, доминирующие церкви находятся в привилегированном положении на религиозном рынке, а потому не имеют мотивации конкурировать за верующих и не могут предложить им необходимые социальные сервисы и поддержку, которые бы стали достойной заменой государственным институтам. Более того, при наличии государственного финансирования церквей верующие в целом будут одобрительно относиться к системе перераспределения, поскольку могут рассчитывать на более эффективную помощь через церковь, но за счет перераспределения средств от налогов. Именно эту теорию развивают Джон Хьюбер и Пьеро Станиг, показывая, что разнонаправленное влияние религиозности на предпочтения относительно перераспределения возникает не из-за регулирования государством религиозного рынка или конфликтующих ценностей на индивидуальном уровне, но из-за степени финансового разделения церкви и государства (Huber, Stanig 2011). Если церкви получают финансирование от государства, то малообеспеченным верующим выгодно поддерживать высокие налоги, так как они смогут получить эти ресурсы через церковь. Когда разделение церкви и государства усиливается, финансирование церквей (и бедных верующих через церковь) стремится к нулю. При низких налогах у богатых остается больше средств, которые они могут пожертвовать на помощь нуждающимся, а тем, в свою очередь, не приходится конкурировать за получение государственной социальной помощи наравне с нерелигиозными нуждающимися. 


\section{Заключение}

Религиозная культура оказала заметное влияние на формирование различных режимов благосостояния в странах Европы, определяя, с одной стороны, какие категории нуждающихся заслуживают помощи, а с другой, кто эту помощь должен оказывать - церковь, государство или же это проблема самих нуждающихся. Последствия доктринальных различий в отношении к бедности в разных ветвях христианства на страновом уровне стираются: в целом во всех развитых странах реализуются программы по поддержке нуждающихся, и дискуссии ведутся скорее по поводу расширения социальной политики на иностранных граждан. Доминирование протестантских традиций индивидуализма не помешало странам Скандинавии создать щедрые режимы благосостояния, которые с течением времени эволюционируют в сторону расширения социальной политики. Пример Швейцарии и Нидерландов показывает, что и сильное влияние кальвинистской традиции не является преградой для создания государственной системы помощи разным категориям нуждающихся. С другой стороны, нельзя не заметить, что на установление и развитие государств благосостояния в странах Европы негативное влияние оказало наличие конфликтов, основанных на религии, будь то противостояние между церковью и государством, как в преимущественно католических странах, либо между последователями разных религиозных традиций, как, например, в Швейцарии и Нидерландах. В исторической перспективе отсутствие консенсуса по поводу того, кто должен заниматься реализацией программ помощи нуждающимся - церковь или государство, а также нужны ли вообще централизованные программы, привело к тому, что даже сегодня жители этих стран демонстрируют более критическое отношение к государственной политике перераспределения в сравнении с жителями стран, где исторически в церковно-государственных отношениях однозначно доминировало государство (как в Скандинавии), а религия не оспаривала право государства на реализацию программ помощи нуждающимся.

На индивидуальном уровне и в XXI в. религия является источником различий в восприятии политики перераспределения: религиозные люди, вне зависимости от принадлежности к конкретной ветви христианства, меньше поддерживают политику перераспределения, чем нерелигиозные. Потенциальная разнонаправленность влияния религиозности в зависимости от отношений церкви и государства, приводит к необходимости дальнейшего кросс-странового изучения взаимосвязи религиозности и восприятия политики перераспределения с учетом таких важных контекстуальных факторов, как финансовые и политические взаимоотношения церкви и государства, а также степень культурной гетерогенности, которая в последние годы заметно увеличивается во всех странах Европы в результате миграции и может стать вызовом для ранее гомогенных стран Скандинавии. 
Anna Kulkova

\section{RELIGION AND SOCIAL JUSTICE: A REVIEW OF THE INFLUENCE OF RELIGIOSITY ON SOCIAL POLICY PREFERENCES}

The generosity of social policy depends on a country's economic development levels, which, in turn, determine how much the state can redistribute and use to help those in need. However, particular social policies in a given country also depend on citizen preferences and their perceptions of whether it is necessary to help certain categories of people in need, as well as how far the state should intervene in the economy. Unlike most studies that explain differences in social policy preferences with reference to socio-economic factors, this literature review focuses on religion as a cultural predictor of welfare attitudes. Religion can influence individual redistribution preferences by creating the overall cultural context and setting the standards for helping those in need, as well as via determining believers' perceptions of who deserves help and how these social support measures should be implemented. The paper offers a review of the mechanisms through which religion can shape individual attitudes towards social policy and, based on these existing studies, analyses whether there are differences in welfare attitudes between followers of different religious traditions, as well as between religious and non-religious individuals in contemporary Europe. Firstly, the paper studies how different modes of interaction between churches and secular states, as well as differences in the content of religious traditions, can lead to the formation of distinctive attitudes towards poverty and, as a consequence, to the formation of distinctive welfare provision regimes in Europe. Following this, the paper reviews how redistribution preferences can be affected by individual religiosity (religious affiliation and degree of religiosity), and identifies the mechanisms through which religion can substitute the state social institutions for its followers.

Key-words: religion, social policy, redistribution preferences, welfare attitudes

DOI: 10.17323/727-0634-2018-16-2-251-264

\section{References}

Achterberg P., Houtman D. (2006) Why do so Many People Vote 'Unnaturally'? A Cultural Explanation for Voting Behaviour. European Journal of Political Research, 45 (1): 75-92.

Alesina A., Fuchs-Schundeln N. (2007) Good-bye Lenin (or not?): The Effect of Communism on People's Preferences. The American Economic Review, 97(4): 1507-1528.

Alesina A., Giuliano P. (2011) Preferences for Redistribution. A. Bisin., J. Benhabib (eds.) Handbook of Social Economics. Amsterdam: Elsevier:93-132.

Anna Kulkova - junior research fellow, Laboratory for Political Studies, NRU HSE, Moscow, Russian Federation. Email: akulkova@hse.ru 
Alesina A., Glaeser E. (2004) Fighting Poverty in the US and Europe. Oxford: Oxford University Press.

Alesina A., Devleeschauwer A., Easterly W., Kurlat S., Wacziarg R. (2003) Fractionalization. Journal of Economic growth, (8): 155-194.

Arikan G. (2013) Values, Religiosity and Support for Redistribution and Social Policy in Turkey. Turkish Studies, 14 (1):34-52.

Bréchon P. (2003) Integration into Catholicism and Protestantism in Europe: The Impact on Moral and Political values. L. Halman., O. Riis (eds.) Religion and Secularizing Society: The Europeans' Religion at the End of the 20th Century, Boston: Brill: 114-161.

Brodman J. (2009) Charity and Religion in Medieval Europe. Washington, D.C.: CUA Press. Bruce S. (2002) God is Dead: Secularization in the West. Oxford: Blackwell Oxford.

Catterall P. (1993) Morality and Politics: The Free Churches and the Labour Party between the Wars. The Historical Journal, 36 (3): 667-685.

Chen D. L., Lind J. T. (2005) The Political Economy of Beliefs: Why Fiscal and Social Conservatives/Liberals Come Hand-in-Hand. Philadelphia: Annual Meeting of the American Political Science Association.

Clark A. E., Lelkes O. (2005) Deliver us from Evil: Religion as Insurance. PSE Working Papers, 43. Cohen J. (2002) Protestantism and Capitalism: The Mechanisms of Influence. New York: A. de Gruyter.

Cook F. L., Barrett E. J. (1992) Support for the American Welfare State: The Views of Congress and the Public. New York: Columbia University Press.

Esping-Andersen G. (1990) The Three Worlds of Welfare Capitalism. Princeton: Princeton University Press.

Giuliano P., Spilimbergo A. (2014) Growing up in a Recession. The Review of Economic Studies, 81 (2): 787-817.

Gorski P. S. (2003) The Disciplinary Revolution: Calvinism and the Rise of the State in Early Modern Europe. Chicago: University of Chicago Press.

Gustafsson G. (2003) Church-state Separation Swedish-style. West European Politics, (26):51-72.

Huber J. D., Stanig P. (2011) Church-state Separation and Redistribution. Journal of Public Economics, 95 (7): 828-836.

Hudson K., Coukos A. (2005) The Dark Side of the Protestant Ethic: A Comparative Analysis of Welfare Reform. Sociological Theory, 23 (1): 1-24.

Iversen T., Soskice D. (2001) An Asset Theory of Social Policy Preferences. American Political Science Review, 95 (4): 875-894.

Kahl S. (2005) The Religious Roots of Modern Poverty Policy: Catholic, Lutheran, and Reformed Protestant Traditions Compared. European Journal of Sociology, 46 (1): 91-126.

Kahl S. (2009) Religion as a Cultural Force: Social Doctrines and Poor Relief Traditions. K. Van Kersbergen., P. Manow (eds.) Religion, Class Coalitions, and Welfare States. Cambridge: Cambridge University Press:263-285.

Kalyvas S. N., Van Kersbergen K. (2010) Christian Democracy. Annual Review of Political Science, (13): 183-209.

Kumlin S. (2007) The Welfare State: Values, Policy Preferences, and Performance Evaluations. R. Dalton., H. Klingemann (eds.) Oxford Handbook of Political Behavior, Oxford: Oxford University Press.

Lepianka D., Gelissen J., Van Oorschot W. (2010) Popular Explanations of Poverty in Europe: Effects of Contextual and Individual Characteristics across 28 European Countries. Acta Sociologica, 53 (1): 53-72. 
Lipsmeyer C., Nordstrom T. (2003) East versus West: Comparing Political Attitudes and Welfare Preferences across European Societies. Journal of European Public Policy, 10 (3):339-364.

Madeley J. (2003) A Framework for the Comparative Analysis of Church-state Relations in Europe. West European Politics, 26 (1): 23-50.

Malka A., Soto C. J., Cohen A. B., Miller D. T. (2011) Religiosity and Social Welfare: Competing Influences of Cultural Conservatism and Prosocial Value Orientation. Journal of Personality, 79 (4): 763-792.

Manow P. (2004) The Good, the Bad, and the Ugly: Esping-Andersen's Regime Typology and the Religious Roots of the Western Welfare State. MPIfG working paper.

Mau S. (2004) The Moral Economy of Welfare States: Britain and Germany Compared. New York: Routledge.

McCleary R. M. (2007) Salvation, Damnation, and Economic Incentives. Journal of Contemporary Religion, 22 (1): 49-74.

Minkenberg M. (2010) Party Politics, Religion and Elections in Western democracies. Comparative European Politics, 8 (4): 385-414.

Molokotos-Liederman L., Fokas E. (2010) The Disgraceful and the Divine in Greek welfare: The Cases of Thiva and Livadeia. A. Backstrom., G. Davie (eds.) Welfare and Religion in 21st Century Europe: Configuring the Connections. Burlington: Ashgate Publishing: 167-182.

Obinger H. (2009) Religion and the Consolidation of the Swiss Welfare State, 1848-1945. K. Van Kersbergen., P. Manow (eds.) Religion, Class Coalitions and Welfare State Regimes. Cambridge: Cambridge University Press: 176-210.

Pepinsky T.B., Welborne B.C. (2011) Piety and Redistributive Preferences in the Muslim world. Political Research Quarterly, 64 (3): 491-505.

Pfau-Effinger B. (2005) Culture and Welfare State Policies: Reflections on a Complex Interrelation. Journal of Social Policy, 34 (1):3-20.

Philpott D. (2007) Explaining the Political Ambivalence of Religion. American Political Science Review, 101 (3): 505-525.

Sanders A. (1988) Rationality, Self-interest, and Public Attitudes on Public Spending. Social Science Quarterly, (69): 311.

Scheve K., Stasavage D. (2006) Religion and Preferences for Social Insurance. Quarterly Journal of Political Science, (3): 255-286.

Stegmueller D. (2013) Religion and Redistributive Voting in Western Europe. The Journal of Politics, 75 (4): 1064-1076.

Svallfors S. (2006) The Moral Economy of Class: Class and Attitudes in Comparative Perspective. Stanford: Stanford University Press.

Van Kersbergen K. (2003) Social Capitalism: A Study of Christian Democracy and the Welfare State. New York: Routledge.

Van Kersbergen K. (2009) Religion and the Welfare State in the Netherlands. K. Van Kersbergen., P. Manow (eds.) Religion, Class Coalitions, and Welfare States. New York: Cambridge University Press: 119-145.

Van Kersbergen K., Manow P. (eds.) (2009) Religion, Class Coalitions, and Welfare States. Cambridge: Cambridge University Press.

Van Oorschot W. (2000) Who Should Get What, and Why? On Deservingness Criteria and the Conditionality of Solidarity among the Public. Policy, Politics, 28 (1):33-48.

Van Oorschot W. (2006) Making the Difference in Social Europe: Deservingness Perceptions among Citizens of European Welfare States. Journal of European social policy, 16 (1):23-42. 